\title{
Association of Vitamin D Deficiency with Diabetic Nephropathy
}

\author{
So-hyeon Hong ${ }^{1}$, Young Bin Kim², Hoon Sung Choi ${ }^{3}$, Tae-Dong Jeong ${ }^{4}$, Jin Taek Kim², Yeon Ah Sung ${ }^{1}$ \\ ${ }^{1}$ Division of Endocrinology and Metabolism, Department of Internal Medicine, Ewha Womans University School of Medicine; \\ ${ }^{2}$ Department of Internal Medicine, Nowon Eulji Medical Center, Eulji University School of Medicine, Seoul; ${ }^{3}$ Department of \\ Internal Medicine, Kangwon National University School of Medicine, Chuncheon; ${ }^{4}$ Department of Laboratory Medicine, Ewha \\ Womans University School of Medicine, Seoul, Korea
}

Background: Low 25-hydroxyvitamin D (25OHD) levels are associated with the incidence of type 2 diabetes mellitus (T2DM). However, the association between 25OHD and metabolic health status or diabetic complications is inconclusive. We evaluated this relationship between vitamin D status and metabolic parameters and complications of T2DM.

Methods: This study included 1,392 patients with T2DM who visited Eulji and Ewha Diabetes Center between January 2011 and August 2016. Anthropometric parameters and laboratory tests including glycated hemoglobin (HbA1c), lipid profile, liver and kidney function, and urinary albumin-to-creatinine ratio (UACR) were evaluated. Diabetic macro- and microvascular complications were determined through a medical record review. Serum $25 \mathrm{OHD}$ concentrations were measured by chemiluminescent immunoassay.

Results: The mean 25OHD level was $16.8 \pm 9.6 \mathrm{ng} / \mathrm{mL}$. Vitamin D deficiency $(<20 \mathrm{ng} / \mathrm{mL})$ and severe deficiency $(<10 \mathrm{ng} / \mathrm{mL})$ were observed in 990 (71.1\%) and 351 (25.2\%) participants, respectively. 25OHD level was positively correlated with age and highdensity lipoprotein cholesterol (HDL-C) level and negatively correlated with HbA1c, triglyceride level, and UACR. HDL-C and UACR were significantly associated with $25 \mathrm{OHD}$ after adjusting for other variables. Vitamin D deficiency was independently related to nephropathy after adjusting for confounding variables.

Conclusion: Vitamin D deficiency was common among Korean T2DM patients; it was independently associated with microalbuminuria and HDL level, and positively related to diabetic nephropathy.

Keywords: Albuminuria; Diabetes complications; Diabetic nephropathies; Vitamin D

\section{INTRODUCTION}

Vitamin D, traditionally known for its role in regulating bone and calcium metabolism, has recently been implicated in a multitude of systems including the cardiovascular, immune, and reproductive systems [1,2]. The ubiquitous expression of vitamin
Received: 27 August 2020, Revised: 5 December 2020,

Accepted: 10 December 2020

Corresponding authors: Yeon Ah Sung

Division of Endocrinology and Metabolism, Department of Internal Medicine, Ewha Womans University Medical Center, 1071 Anyangcheon-ro, Yangcheon-gu, Seoul 07985, Korea

Tel: +82-2-2650-5034, Fax: +82-2-2650-5235, E-mail: yasung@ewha.ac.kr

Jin Taek Kim

Division of Endocrinology and Metabolism, Department of Internal Medicine,

Nowon Eulji Medical Center, Eulji University School of Medicine,

68 Hangeulbiseong-ro, Nowon-gu, Seoul 01830, Korea

Tel: +82-2-970-8456, Fax: +82-2-970-8862, E-mail: jtkimmd@eulji.ac.kr

\section{Copyright $\odot 2021$ Korean Endocrine Society}

This is an Open Access article distributed under the terms of the Creative Commons Attribution Non-Commercial License (https://creativecommons.org/ licenses/by-nc/4.0/) which permits unrestricted non-commercial use, distribution, and reproduction in any medium, provided the original work is properly cited. 
D receptors in the human body is closely related to these findings, suggesting that vitamin D plays an important role in the regulation of the expression of multiple genes beyond those involved in calcium metabolism [3].

Several large epidemiologic studies on the impact of vitamin $\mathrm{D}$ on metabolic and cardiovascular diseases demonstrated that lower vitamin D levels were associated with the incidence of type 2 diabetes mellitus (T2DM) [4,5]. Vitamin D deficiency reportedly reduced intracellular calcium levels and decreased insulin secretion in pancreatic beta cells [6]. Vitamin D deficiency also decreases the insulin receptor expression, leading to peripheral insulin resistance [7]. Furthermore, vitamin D deficiency has an atherosclerotic action, promoting myocardial hypertrophy and renin activation [8].

Vitamin D deficiency is prevalent in South Korea. The 2006 to 2008 Korea National Health and Nutrition Examination Survey (KNHANES), which included adults aged 19 years or older, reported vitamin D deficiency in $47.3 \%$ of men and $64.5 \%$ of women [9]. Another international study reported that Korean postmenopausal osteoporotic women had the lowest 25-hydroxyvitamin D (25OHD) levels among 18 countries [10]. These findings suggest that vitamin D deficiency may be even more prevalent in T2DM patients in Korea and related to poor glycemic control and/or various complications of T2DM.

However, studies on the association between vitamin D deficiency and micro- and macrovascular complications in T2DM showed conflicting results and are currently inconclusive. Several studies reported that vitamin D deficiency increased the risk of diabetic polyneuropathy [11], nephropathy, and retinopathy [12]. However, other studies found no association between vitamin D deficiency and diabetic polyneuropathy [13] or retinopathy [14]. While vitamin D deficiency was reportedly associated with a lower low-density lipoprotein cholesterol (LDL-C) level and a higher triglyceride level and diastolic blood pressure than those in T2DM patients with sufficient vitamin D level [15], other studies reported no relationship [16].

The present study investigated the prevalence of vitamin D deficiency in Korean patients with T2DM and identified the relationship between vitamin D status and diabetes-related parameters such as glycemic control, macro- and microvascular complications, and cardiovascular risk factors.

\section{METHODS}

\section{Study population}

This cross-sectional study included 1,564 T2DM patients who visited Eulji Diabetes Center and Ewha Womans University Mokdong Hospital between January 2011 and August 2016. T2DM was diagnosed according to the American Diabetes Association criteria [17]. We excluded patients who took calcium or vitamin D supplements, and patients with diagnosed osteoporosis, chronic kidney stage 5 (estimated glomerular filtration rate $[\mathrm{eGFR}]<15 \mathrm{~mL} / \mathrm{min} / 1.73 \mathrm{~m}^{2}$ ), liver cirrhosis, or refractory malignancy. Finally, 1,392 patients were included in the analysis. The Institutional Review Boards of the hospitals approved the study (EMCIRB 09-007 and EUMC 2016-07-013-002), and due to a retrospective nature of the study, informed consent was waived.

\section{Anthropometric and biochemical measurements}

We collected information on age, sex, smoking status, alcohol consumption, duration of diabetes, and types of diabetic medication used from patient medical records. Height and weight were measured, and body mass index (BMI) was calculated by dividing the weight in kilograms by the height squared in meters. The blood pressure was calculated as the mean of two manual sphygmomanometer readings with the patient in a seated position.

A venous blood sample was collected after an overnight fast for at least 8 hours. 25OHD levels were measured using a chemiluminescent immunoassay (Roche ELECSYS ${ }^{\circledR}$, Total Vitamin D, Roche Diagnostics, Mannheim, Germany; and Liaison ${ }^{\circledR}$ 25-OH Vitamin D Total, DiaSorin, Saluggia, Italy). According to the World Health Organization definitions, vitamin D status was defined as following: severely deficient for $25 \mathrm{OHD}<10$ $\mathrm{ng} / \mathrm{mL}$, deficient for $10 \mathrm{ng} / \mathrm{mL} \leq 25 \mathrm{OHD}<20 \mathrm{ng} / \mathrm{mL}$, insufficient for $20 \mathrm{ng} / \mathrm{mL} \leq 25 \mathrm{OHD}<30 \mathrm{ng} / \mathrm{mL}$, and sufficient for $25 \mathrm{OHD} \geq 30 \mathrm{ng} / \mathrm{mL}$ [18].

Glycated hemoglobin (HbA1c) was measured by high-performance liquid chromatography using HLC-723G7 and G8 instruments (Tosoh, Tokyo, Japan). Total cholesterol, LDL-C, high-density lipoprotein cholesterol (HDL-C), triglyceride, and creatinine levels were measured using enzymatic colorimetric procedures with an automated analyzer (Hitachi-747, Hitachi, Tokyo, Japan). Total calcium and phosphorus were measured using CA-HR2 and P-HR2 (Wako Pure Chemical Industries, Osaka, Japan), respectively. The eGFR was calculated using the following Modification of Diet in Renal Disease equation: $186 \times(\text { serum creatinine })^{-1.154} \times(\text { age })^{-0.203} \times(0.742$ if female $)[19]$. The urinary albumin-to-creatinine ratio (UACR) was assessed on a random spot urine sample and measured using radioimmunoassay (Immunotech, Prague, Czech Republic). 


\section{Assessment of diabetic complications}

The presence of diabetic retinopathy, nephropathy, neuropathy, and cardio and cerebrovascular diseases (CVDs) were investigated through medical record reviews. Diabetic retinopathy was defined as either a non-proliferative or proliferative diabetic retinopathy or previous laser photocoagulation therapy. Diabetic nephropathy was defined as microalbuminuria (UACR 30 to $299 \mathrm{mg} / \mathrm{g}$ ) or macroalbuminuria (UACR $\geq 300 \mathrm{mg} / \mathrm{g}$ ). Diabetic neuropathy was identified in patients by the current perception threshold test (CPT) using a Neurometer (Neurotron Inc., Baltimore, MD, USA) or reported pain, burning, tingling, or numb sensation on the feet or hands. CVD included myocardial infarction, unstable angina, or stroke.

\section{Statistical analysis}

The statistical analysis was performed using IBM SPSS Statistics for Windows version 20.0 (IBM Corp., Armonk, NY, USA). Quantitative variables were reported as means and standard deviations and categorical parameters were reported as numbers and percentages. Student's $t$ test and chi-square test were used for comparisons between groups with continuous and categorical variables, respectively.

The 25OHD levels showed significant seasonal variance, with a significantly lower level during the winter season compared to those in the spring, summer, and autumn after Bonferroni correction $(14.4 \pm 9.5,18.2 \pm 10.8,17.1 \pm 8.8$, and $17.7 \pm 9.1 \mathrm{ng} / \mathrm{mL}$, respectively, $P$ for trend $<0.01)$. Therefore, we also adjusted for seasonal variation to winter (from December to February) versus non-winter (from March to November).

Pearson's correlation tests were used to evaluate the relationships between 25OHD level and diabetes-related clinical and biochemical parameters. Multiple linear regression analysis was performed using the 25OHD levels as independent variables and $\mathrm{HbA1c}$, eGFR, total, LDL-C, and HDL-C, triglycerides, and UACR as dependent variables to determine the relationships between 25OHD levels and diabetes-related factors. Multiple logistic regression was performed to identify the independent association between vitamin $\mathrm{D}$ deficiency and macro- and microvascular complications. Two-tailed $P$ values $<0.05$ were considered statistically significant.

\section{RESULTS}

\section{Basal characteristics}

The mean age of the participants was $61.6 \pm 10.9$ years, $57.9 \%$ were men, and the mean BMI was $25.8 \pm 3.6 \mathrm{~kg} / \mathrm{m}^{2}$. The mean
HbA1c was $7.4 \% \pm 1.3 \%$, the mean duration of diabetes was $13.0 \pm 8.0$ years, and $18.5 \%$ of patients used insulin. Retinopathy, nephropathy, neuropathy, and CVD were present in $30.3 \%$, $31.2 \%, 17.2 \%$, and $15.6 \%$ of patients, respectively (Supplemental Table S1).

The mean 25OHD level was $16.8 \pm 9.6 \mathrm{ng} / \mathrm{mL}$. Overall, only 144 patients $(10.3 \%)$ showed sufficient $25 \mathrm{OHD}$ levels; 351 patients $(25.2 \%)$ had severe deficiency $(<10 \mathrm{ng} / \mathrm{mL}), 639$ patients (45.9\%) had 25OHD levels of $10 \leq$ and $<20 \mathrm{ng} / \mathrm{mL}$, and 258 patients $(18.5 \%)$ had values of $20 \leq$ and $<30 \mathrm{ng} / \mathrm{mL}$ (Supplemental Table S2).

The clinical and metabolic characteristics of the participants stratified by vitamin D deficiency status are presented in Table 1. Among patients with T2DM, those with vitamin D deficiency were younger (60.9 years vs. 63.3 years, $P<0.01)$ and had higher HbAlc (7.5\% vs. 7.2\%, $P<0.01)$, lower HDL-C $(47.3 \mathrm{mg} / \mathrm{dL}$ vs. $50.7 \mathrm{mg} / \mathrm{dL}, P<0.01)$, and higher triglyceride $(164.2 \mathrm{mg} / \mathrm{dL}$ vs. $148.7 \mathrm{mg} / \mathrm{dL}, P=0.01)$ levels as well as higher UACR (129.1 $\mathrm{mg} / \mathrm{g}$ vs. $50.6 \mathrm{mg} / \mathrm{g}, P<0.01)$ compared to those in participants without vitamin $\mathrm{D}$ deficiency. While a higher percentage of vitamin D-deficient participants used insulin (20.4\% vs. $13.7 \%$, $P<0.01$ ), the duration of diabetes did not differ between the two groups. Additionally, nephropathy was more prevalent in patients with a vitamin D deficiency than in in patients without a vitamin D deficiency (34.0\% vs. $24.3 \%, P<0.01)$. Other complications did not differ between the two groups.

\section{Correlations between $250 H D$ levels and clinical and biochemical variables}

We observed a significant positive correlation between $25 \mathrm{OHD}$ level and age $(r=0.05, P=0.045)$ and HDL-C $(r=0.12, P<0.01)$ and negative associations between 25OHD and HbAlc $(r=$ $-0.09, P<0.01)$, triglycerides $(r=-0.08, P<0.01)$, and UACR $(r=-0.13, P<0.01)$ (Table 2).

\section{Association between 250HD and diabetes-related clinical and biochemical variables}

Correlation analysis through multiple linear regression was performed to identify biochemical variables associated with $25 \mathrm{OHD}$ levels. The 25OHD level was positively associated with HDL-C $(\beta=5.56 ; 95 \%$ confidence interval $[\mathrm{CI}], 1.32$ to 9.81; $P=0.01)$ and negatively associated with UACR $(\beta=-194$; $95 \% \mathrm{CI},-290$ to $-98.0 ; P<0.01)$ after adjusting for age, sex, systolic blood pressure, HbA1c, total calcium, phosphorus, duration of diabetes, type of medication, and season (Table 3). 
Table 1. Baseline Characteristics According to Vitamin D Deficiency Status

\begin{tabular}{|c|c|c|c|}
\hline Characteristic & $\begin{array}{c}25 \mathrm{OHD} \\
<20 \mathrm{ng} / \mathrm{mL} \\
(n=990)\end{array}$ & $\begin{array}{c}25 \mathrm{OHD} \\
\geq 20 \mathrm{ng} / \mathrm{mL} \\
(n=402)\end{array}$ & $P$ value \\
\hline Age, yr & $60.9 \pm 11.1$ & $63.3 \pm 10.2$ & $<0.01$ \\
\hline Male, sex & $566(57.2)$ & $240(59.7)$ & 0.40 \\
\hline BMI, $\mathrm{kg} / \mathrm{m}^{2}$ & $25.9 \pm 3.6$ & $25.6 \pm 3.6$ & 0.17 \\
\hline SBP, $\mathrm{mm} \mathrm{Hg}$ & $133 \pm 16$ & $132 \pm 15$ & 0.17 \\
\hline DBP, mm Hg & $78 \pm 11$ & $77 \pm 10$ & 0.10 \\
\hline $\begin{array}{l}\text { Smoking status }(n=1,246) \\
\text { (former or current) }\end{array}$ & $355(39.7)$ & $153(43.5)$ & 0.23 \\
\hline $\begin{array}{l}\text { Alcohol status }(n=1,248) \\
\quad \text { (yes) }\end{array}$ & $355(39.7)$ & $178(50.4)$ & $<0.01$ \\
\hline $\mathrm{HbAlc}, \%$ & $7.5 \pm 1.4$ & $7.2 \pm 1.1$ & $<0.01$ \\
\hline Total cholesterol, mg/dL & $166 \pm 37$ & $168 \pm 35$ & 0.45 \\
\hline LDL-C, mg/dL & $92.2 \pm 29.2$ & $92.8 \pm 29.1$ & 0.71 \\
\hline HDL-C, mg/dL & $47.3 \pm 12.0$ & $50.7 \pm 11.8$ & $<0.01$ \\
\hline Triglycerides, mg/dL & $164.2 \pm 109.5$ & $148.7 \pm 86.4$ & 0.01 \\
\hline AST, IU/L & $25.7 \pm 14.4$ & $27.2 \pm 23.1$ & 0.15 \\
\hline ALT, IU/L & $27.0 \pm 19.4$ & $26.6 \pm 21.4$ & 0.71 \\
\hline Creatinine, mg/dL & $1.03 \pm 0.29$ & $1.01 \pm 0.21$ & 0.23 \\
\hline $\begin{array}{l}\text { eGFR (MDRD), } \mathrm{mL} / \\
\min / 1.73 \mathrm{~m}^{2}\end{array}$ & $69.8 \pm 17.8$ & $69.4 \pm 15.1$ & 0.68 \\
\hline UACR, mg/g & $129.1 \pm 481.0$ & $50.6 \pm 148.9$ & $<0.01$ \\
\hline Total calcium, mg/dL & $9.0 \pm 0.5$ & $8.9 \pm 0.6$ & 0.02 \\
\hline Phosphorus, mg/dL & $3.5 \pm 0.8$ & $3.6 \pm 0.8$ & 0.32 \\
\hline Duration of diabetes, yr & $12.8 \pm 8.1$ & $13.6 \pm 7.9$ & 0.10 \\
\hline Medication (any insulin) & $201(20.4)$ & $55(13.7)$ & $<0.01$ \\
\hline \multicolumn{4}{|l|}{ Complication } \\
\hline Retinopathy $(n=931)$ & $214 / 690(31.0)$ & $68 / 241(28.2)$ & 0.46 \\
\hline Neuropathy $(n=1,367)$ & 173/974 (17.8) & 62/393 (28.7) & 0.43 \\
\hline Nephropathy $(n=1,354)$ & $329 / 967(34.0)$ & $94 / 387(24.3)$ & $<0.01$ \\
\hline Cardiovascular disease & $158(16.0)$ & $59(14.7)$ & 0.57 \\
\hline
\end{tabular}

Values are expressed as mean \pm standard deviation or number (\%).

25OHD, 25-hydroxyvitamin D; BMI, body mass index; SBP, systolic blood pressure; DBP, diastolic blood pressure; HbA1c, glycated hemoglobin; LDL-C, low-density lipoprotein cholesterol; HDL-C, high-density lipoprotein cholesterol; AST, aspartate aminotransferase; ALT, alanine transaminase; eGFR, estimated glomerular filtration rate; MDRD, Modification of Diet in Renal Disease; UACR, urinary albumin-to-creatinine ratio.

\section{Association between vitamin D deficiency and macro- and microvascular complications}

Using the vitamin D insufficiency and sufficiency groups as a reference, the vitamin D deficiency group showed an increased

\begin{tabular}{|c|c|c|}
\hline Variable & $r$ & $P$ value \\
\hline Age & 0.05 & 0.045 \\
\hline BMI & -0.04 & 0.13 \\
\hline SBP & -0.04 & 0.15 \\
\hline DBP & -0.05 & 0.06 \\
\hline $\mathrm{HbAlc}$ & -0.09 & $<0.01$ \\
\hline Total cholesterol & -0.02 & 0.53 \\
\hline LDL-C & -0.02 & 0.49 \\
\hline HDL-C & 0.12 & $<0.01$ \\
\hline Triglycerides & -0.08 & $<0.01$ \\
\hline AST & 0.03 & 0.29 \\
\hline ALT & 0.01 & 0.66 \\
\hline eGFR (MDRD) & 0.05 & 0.09 \\
\hline UACR & -0.13 & $<0.01$ \\
\hline Total calcium & -0.23 & 0.40 \\
\hline Phosphorus & -0.02 & 0.48 \\
\hline Duration of diabetes & 0.05 & 0.07 \\
\hline \multicolumn{3}{|c|}{$\begin{array}{l}25 \mathrm{OHD} \text { and triglyceride levels were computed from log-scale. } \\
25 \mathrm{OHD}, 25 \text {-hydroxyvitamin D; BMI, body mass index; SBP, systolic } \\
\text { blood pressure; DBP, diastolic blood pressure; HbAlc, glycated hemo- } \\
\text { globin; LDL-C, low-density lipoprotein cholesterol; HDL-C, high-den- } \\
\text { sity lipoprotein cholesterol; AST, aspartate aminotransferase; ALT, ala- } \\
\text { nine transaminase; eGFR, estimated glomerular filtration rate; MDRD, } \\
\text { Modification of Diet in Renal Disease; UACR, urinary albumin-to-cre- } \\
\text { atinine ratio. }\end{array}$} \\
\hline
\end{tabular}

risk of nephropathy after adjusting for age, sex, systolic blood pressure, $\mathrm{HbAlc}$, total calcium, phosphorus, duration of diabetes, type of medication, and season (odds ratio, 1.62; 95\% CI, 1.21 to $2.16 ; P<0.01$ ) (Table 4). Retinopathy, neuropathy, and CVD were not related to vitamin $\mathrm{D}$ deficiency.

\section{DISCUSSION}

In this study, the 25OHD levels in T2DM patients were correlated with several clinical parameters of diabetes, including HbAlc, albuminuria, triglyceride, and HDL. Among diabetic macro- and microvascular complications, diabetic nephropathy was correlated with the $25 \mathrm{OHD}$ level. In particular, the $25 \mathrm{OHD}$ level remained an independent risk factor for diabetic nephropathy after adjusting for the other risk factors.

In our study, the rate of vitamin D deficiency (defined as less than $20 \mathrm{ng} / \mathrm{mL}$ ) was $71.1 \%$, while that for severe deficiency (less than $10 \mathrm{ng} / \mathrm{mL}$ ) was $25.2 \%$. This prevalence was higher 


\begin{tabular}{|c|c|c|c|c|c|c|}
\hline \multirow{2}{*}{ Variable } & \multicolumn{3}{|c|}{ Model 1} & \multicolumn{3}{|c|}{ Model 2} \\
\hline & $\beta$ & $95 \% \mathrm{CI}$ & $P$ value & $\beta$ & $95 \% \mathrm{CI}$ & $P$ value \\
\hline $\mathrm{HbA1c}$ & -0.48 & -0.76 to -0.19 & $<0.01$ & & & \\
\hline Total cholesterol & -0.97 & -8.51 to 6.57 & 0.80 & 5.56 & -2.31 to 13.43 & 0.17 \\
\hline LDL-C & -1.16 & -7.43 to 5.12 & 0.72 & 0.01 & -6.63 to 6.66 & 0.99 \\
\hline HDL-C & 5.88 & 2.17 to 9.60 & $<0.01$ & 5.56 & 1.32 to 9.81 & 0.01 \\
\hline Triglycerides & -0.09 & -0.15 to -0.04 & $<0.01$ & -0.04 & -0.09 to 0.01 & 0.12 \\
\hline eGFR & 4.48 & 1.11 to 7.85 & 0.01 & 1.82 & -1.27 to 4.90 & 0.25 \\
\hline UACR & -225 & -314 to -136 & $<0.01$ & -194 & -290 to -98.0 & $<0.01$ \\
\hline \multicolumn{7}{|c|}{$\begin{array}{l}\text { Model 1: Adjusted for age; Model 2: Adjusted for age, sex, body mass index, systolic blood pressure, HbA1c, total calcium, phosphorus, duration of dia- } \\
\text { betes, type of medication, and season. } 25 \mathrm{OHD} \text { and triglyceride levels were computed from log-scale. } \\
\text { 25OHD, 25-hydroxyvitamin D; CI, confidence interval; HbAlc, glycated hemoglobin; LDL-C, low-density lipoprotein cholesterol; HDL-C, high-densi- } \\
\text { ty lipoprotein cholesterol; eGFR, estimated glomerular filtration rate; UACR, urinary albumin-to-creatinine ratio. }\end{array}$} \\
\hline
\end{tabular}

Table 4. Logistic Regression Analysis of the Association between Vitamin D Deficiency and Diabetic Complications

\begin{tabular}{|c|c|c|c|c|c|c|}
\hline \multirow{2}{*}{ Variable } & \multicolumn{3}{|c|}{ Model 1} & \multicolumn{3}{|c|}{ Model 2} \\
\hline & OR & $95 \% \mathrm{CI}$ & $P$ value & OR & $95 \% \mathrm{CI}$ & $P$ value \\
\hline Retinopathy & 1.17 & $0.85-1.62$ & 0.34 & 1.30 & $0.90-1.88$ & 0.16 \\
\hline Nephropathy & 1.72 & $1.31-2.26$ & $<0.01$ & 1.62 & $1.21-2.16$ & $<0.01$ \\
\hline Neuropathy & 1.21 & $0.88-1.67$ & 0.24 & 1.31 & $0.93-1.84$ & 0.12 \\
\hline Cardiovascular disease & 1.20 & $0.86-1.66$ & 0.28 & 1.22 & $0.87-1.72$ & 0.26 \\
\hline
\end{tabular}

Model 1: Adjusted for age; Model 2: Adjusted for age, sex, body mass index, systolic blood pressure, glycated hemoglobin, total calcium, phosphorus, duration of diabetes, type of medication, and season.

OR, odds ratio; CI, confidence interval.

than that in the 2006 to 2008 KNHANES, in which $47.3 \%$ and $64.5 \%$ of the included adult male and female patients aged 19 years, respectively, were vitamin D-deficient [9]. Vitamin D level was affected by age, obesity, sun exposure, and even diabetes itself; in comparison to that in the KNHANES, our study population was older and more obese and had a longer duration of diabetes. A previous study including 9,524 patients with T2DM aged 50 to 75 years in Australia, New Zealand, and Finland reported vitamin D deficiency in $47.9 \%$ of the population [20]. In Asia, two Korean studies reported rates of $18.9 \%$ to $54 \%$ [13,21], a Japanese study reported a rate of $70.6 \%$ [22], and a Chinese study reported a rate of $34.3 \%$ [23]. Additionally, another study on Asians living in the UK reported an $83 \%$ prevalence of vitamin D deficiency among T2DM patients [24]. The broad ranges of vitamin D status among the studies may be attributed to differences in ethnicity, geography, season, sun exposure, physical activity, age, and glycemic control status.
In the present study, 25OHD level was negatively associated with UACR, and vitamin D deficiency was significantly associated with diabetic nephropathy after adjusting for multidirectional variable parameters including age, sex, systolic blood pressure, duration of diabetes, type of medication, total calcium, phosphorus, $\mathrm{HbAlc}$, and season comparable to the findings of a previous study reporting that vitamin $\mathrm{D}$ deficiency increased the risk of diabetic nephropathy progression [25]. An in vitro study showed that vitamin $\mathrm{D}$ has a protective effect in the kidneys by reducing levels of transforming growth factor- $\beta$ and SMAD3 proteins, which are involved in renal fibrosis and oxidative stress [26]. In an animal study, diabetic vitamin D receptor knockout mice developed severe albuminuria compared to diabetic wild-type mice [27]. A clinical study reported that $2 \mu \mathrm{g} /$ day supplementation of paricalcitol reduced microalbuminuria in patients with diabetic nephropathy [28]. Taken together, these findings demonstrate the negative effects of vitamin D deficien- 
cy on albuminuria and diabetic nephropathy. However, we found no association between the 25OHD level and retinopathy or neuropathy in the present study. Several studies have demonstrated the association between vitamin D deficiency and diabetic retinopathy $[29,30]$, while others found no relationship $[14,31]$. In the case of neuropathy, the data suggest that vitamin $\mathrm{D}$ deficiency was associated with neuropathy [32-34]. We did not perform identical methods or use the same diagnostic tools to detect diabetic neuropathy in all patients, which might have increased the false-negative rates; i.e., patients with diabetic neuropathy who did not undergo vibration perception threshold examination nor report abnormal sensations in their feet or hands who could have been considered non-neuropathic patients.

We found that vitamin D deficiency was associated with hypertriglyceridemia and low HDL level and that HDL remained statistically significant after adjusting for other variables. These results are in line with those of previous large-scale general population studies reporting an association between lower vitamin D levels and higher triglyceride and lower HDL levels $[35,36]$. Another study reported that vitamin D level was positively associated with lipoprotein lipase activity, which acted as a triglyceride hydrolase and bridging factor for receptor-mediated lipoprotein uptake [37]. A study on macrophages extracted from obese, hypertensive T2DM patients showed that activated vitamin D signaling prevented foam cell formation in the macrophages, which is an early sign of atherosclerosis [38]. Together, these observations indicate an association between a lower vitamin D level and unfavorable lipid profiles. However, a previous study of T2DM patients reported insignificant results; the relationship between vitamin $\mathrm{D}$ concentration and triglycerides and/or HDL levels disappeared after adjusting for BMI or waist circumference [16]. One possible explanation is that patients with T2DM have ameliorated lipid metabolism compared to that in the general population, which overwhelms the effect of vitamin D on lipid profiles. Another possibility is that even though we did not consider the number of patients taking statins or fibrates, most patients are prescribed individualized doses or types of lipid-lowering agents to reach lipid targets. The average triglyceride and LDL-C levels in the present study were 160 and $92.4 \mathrm{mg} / \mathrm{dL}$, respectively, indicating that these levels nearly optimal.

The strengths of our study include the large study population and the statistically adjustment for seasonal variations. Although we did not measure parathyroid hormone levels, we did adjust for both calcium and phosphorus levels, which are closely relat- ed to vitamin D and the parathyroid hormone. The limitations were that we were unable to determine the physical activity and medications status other than that for diabetes, such as renin-angiotensin blocker of the patients. Furthermore, we could not fully account for neuropathy since we relied on medical records for patients' subjective reports and CPTs conducted before study initiation. Lastly, the cross-sectional design makes it difficult to establish causality.

In conclusion, vitamin $\mathrm{D}$ deficiency was highly prevalent among Korean patients with T2DM and was independently associated with increased diabetic nephropathy. Additionally, low vitamin D levels were related to higher triglyceride and lower HDL-C levels in T2DM patients. Additional prospective studies are needed to evaluate the effect of vitamin D on lipid metabolism and diabetic complications.

\section{CONFLICTS OF INTEREST}

No potential conflict of interest relevant to this article was reported.

\section{AUTHOR CONTRIBUTIONS}

Conception or design: S.H., J.T.K., Y.A.S. Acquisition, analysis, or interpretation of data: S.H., Y.B.K., H.S.C., T.D.J., J.T.K., Y.A.S. Drafting the work or revising: S.H., J.T.K., Y.A.S. Final approval of the manuscript: S.H., Y.B.K., H.S.C., T.D.J., J.T.K., Y.A.S.

\section{ORCID}

So-hyeon Hong https://orcid.org/0000-0001-5194-8924

Yeon Ah Sung https://orcid.org/0000-0002-5120-7365

Jin Taek Kim https://orcid.org/0000-0001-7389-4867

\section{REFERENCES}

1. Chen L, Magliano DJ, Zimmet PZ. The worldwide epidemiology of type 2 diabetes mellitus: present and future perspectives. Nat Rev Endocrinol 2011;8:228-36.

2. Kannel WB, McGee DL. Diabetes and cardiovascular risk factors: the Framingham study. Circulation 1979;59:8-13.

3. Thacher TD, Clarke BL. Vitamin D insufficiency. Mayo Clin Proc 2011;86:50-60.

4. Pittas AG, Lau J, Hu FB, Dawson-Hughes B. The role of vitamin $\mathrm{D}$ and calcium in type 2 diabetes. A systematic review 
and meta-analysis. J Clin Endocrinol Metab 2007;92:201729.

5. Scragg R, Sowers M, Bell C; Third National Health and Nutrition Examination Survey. Serum 25-hydroxyvitamin D, diabetes, and ethnicity in the Third National Health and Nutrition Examination Survey. Diabetes Care 2004;27:2813-8.

6. Maestro B, Campion J, Davila N, Calle C. Stimulation by 1,25-dihydroxyvitamin D3 of insulin receptor expression and insulin responsiveness for glucose transport in U-937 human promonocytic cells. Endocr J 2000;47:383-91.

7. Bland R, Markovic D, Hills CE, Hughes SV, Chan SL, Squires PE, et al. Expression of 25-hydroxyvitamin D3-1alpha-hydroxylase in pancreatic islets. J Steroid Biochem Mol Biol 2004;89-90:121-5.

8. Wang TJ, Pencina MJ, Booth SL, Jacques PF, Ingelsson E, Lanier K, et al. Vitamin D deficiency and risk of cardiovascular disease. Circulation 2008;117:503-11.

9. Choi HS, Oh HJ, Choi H, Choi WH, Kim JG, Kim KM, et al. Vitamin D insufficiency in Korea: a greater threat to younger generation: the Korea National Health and Nutrition Examination Survey (KNHANES) 2008. J Clin Endocrinol Metab 2011;96:643-51.

10. Lips P, Hosking D, Lippuner K, Norquist JM, Wehren L, Maalouf G, et al. The prevalence of vitamin D inadequacy amongst women with osteoporosis: an international epidemiological investigation. J Intern Med 2006;260:245-54.

11. Abbott CA, Malik RA, van Ross ER, Kulkarni J, Boulton AJ. Prevalence and characteristics of painful diabetic neuropathy in a large community-based diabetic population in the U.K. Diabetes Care 2011;34:2220-4.

12. Diaz VA, Mainous AG 3rd, Carek PJ, Wessell AM, Everett CJ. The association of vitamin D deficiency and insufficiency with diabetic nephropathy: implications for health disparities. J Am Board Fam Med 2009;22:521-7.

13. Jung CH, Kim KJ, Kim BY, Kim CH, Kang SK, Mok JO. Relationship between vitamin D status and vascular complications in patients with type 2 diabetes mellitus. Nutr Res 2016;36:117-24.

14. Alam U, Amjad Y, Chan AW, Asghar O, Petropoulos IN, Malik RA. Vitamin D deficiency is not associated with diabetic retinopathy or maculopathy. J Diabetes Res 2016; 2016:6156217.

15. Zoppini G, Galletti A, Targher G, Brangani C, Pichiri I, Trombetta M, et al. Lower levels of 25-hydroxyvitamin D3 are associated with a higher prevalence of microvascular complications in patients with type 2 diabetes. BMJ Open
Diabetes Res Care 2015;3:e00058.

16. Yilmaz H, Kaya M, Sahin M, Delibasi T. Is vitamin D status a predictor glycaemic regulation and cardiac complication in type 2 diabetes mellitus patients? Diabetes Metab Syndr 2012;6:28-31.

17. American Diabetes Association. 2. Classification and diagnosis of diabetes: standards of medical care in diabetes-2019. Diabetes Care 2019;42(Suppl 1):S13-28.

18. Holick MF, Binkley NC, Bischoff-Ferrari HA, Gordon CM, Hanley DA, Heaney RP, et al. Evaluation, treatment, and prevention of vitamin D deficiency: an Endocrine Society clinical practice guideline. J Clin Endocrinol Metab 2011; 96:1911-30.

19. Levey AS, Bosch JP, Lewis JB, Greene T, Rogers N, Roth D. A more accurate method to estimate glomerular filtration rate from serum creatinine: a new prediction equation. Modification of Diet in Renal Disease Study Group. Ann Intern Med 1999;130:461-70.

20. Herrmann M, Sullivan DR, Veillard AS, McCorquodale T, Straub IR, Scott R, et al. Serum 25-hydroxyvitamin D: a predictor of macrovascular and microvascular complications in patients with type 2 diabetes. Diabetes Care 2015;38:5218.

21. Ryu OH, Lee S, Yu J, Choi MG, Yoo HJ, Mantero F. A prospective randomized controlled trial of the effects of vitamin D supplementation on long-term glycemic control in type 2 diabetes mellitus of Korea. Endocr J 2014;61:167-76.

22. Suzuki A, Kotake M, Ono Y, Kato T, Oda N, Hayakawa N, et al Hypovitaminosis $\mathrm{D}$ in type 2 diabetes mellitus: association with microvascular complications and type of treatment. Endocr J 2006;53:503-10.

23. Yiu YF, Chan YH, Yiu KH, Siu CW, Li SW, Wong LY, et al. Vitamin D deficiency is associated with depletion of circulating endothelial progenitor cells and endothelial dysfunction in patients with type 2 diabetes. J Clin Endocrinol Metab 2011;96:E830-5.

24. Tahrani AA, Ball A, Shepherd L, Rahim A, Jones AF, Bates A. The prevalence of vitamin D abnormalities in South Asians with type 2 diabetes mellitus in the UK. Int J Clin Pract 2010;64:351-5.

25. Fernandez-Juarez G, Luno J, Barrio V, de Vinuesa SG, Praga $\mathrm{M}$, Goicoechea $\mathrm{M}$, et al. $25(\mathrm{OH})$ vitamin D levels and renal disease progression in patients with type 2 diabetic nephropathy and blockade of the renin-angiotensin system. Clin J Am Soc Nephrol 2013;8:1870-6.

26. Plum LA, Zella JB. Vitamin D compounds and diabetic ne- 
phropathy. Arch Biochem Biophys 2012;523:87-94.

27. Zhang Z, Sun L, Wang Y, Ning G, Minto AW, Kong J, et al. Renoprotective role of the vitamin $\mathrm{D}$ receptor in diabetic nephropathy. Kidney Int 2008;73:163-71.

28. de Zeeuw D, Agarwal R, Amdahl M, Audhya P, Coyne D, Garimella T, et al. Selective vitamin D receptor activation with paricalcitol for reduction of albuminuria in patients with type 2 diabetes (VITAL study): a randomised controlled trial. Lancet 2010;376:1543-51.

29. He R, Shen J, Liu F, Zeng H, Li L, Yu H, et al. Vitamin D deficiency increases the risk of retinopathy in Chinese patients with type 2 diabetes. Diabet Med 2014;31:1657-64.

30. Jee D, Han KD, Kim EC. Inverse association between high blood 25-hydroxyvitamin $\mathrm{D}$ levels and diabetic retinopathy in a representative Korean population. PLoS One 2014;9: e115199.

31. Patrick PA, Visintainer PF, Shi Q, Weiss IA, Brand DA. Vitamin $\mathrm{D}$ and retinopathy in adults with diabetes mellitus. Arch Ophthalmol 2012;130:756-60.

32. Soderstrom LH, Johnson SP, Diaz VA, Mainous AG 3rd. Association between vitamin $\mathrm{D}$ and diabetic neuropathy in a nationally representative sample: results from 2001-2004 NHANES. Diabet Med 2012;29:50-5.

33. Lv WS, Zhao WJ, Gong SL, Fang DD, Wang B, Fu ZJ, et al.
Serum 25-hydroxyvitamin D levels and peripheral neuropathy in patients with type 2 diabetes: a systematic review and meta-analysis. J Endocrinol Invest 2015;38:513-8.

34. Skalli S, Muller M, Pradines S, Halimi S, Wion-Barbot N. Vitamin D deficiency and peripheral diabetic neuropathy. Eur J Intern Med 2012;23:e67-8.

35. Skaaby T, Husemoen LL, Martinussen T, Thyssen JP, Melgaard $\mathrm{M}$, Thuesen $\mathrm{BH}$, et al. Vitamin D status, filaggrin genotype, and cardiovascular risk factors: a Mendelian randomization approach. PLoS One 2013;8:e57647.

36. Martins D, Wolf M, Pan D, Zadshir A, Tareen N, Thadhani $\mathrm{R}$, et al. Prevalence of cardiovascular risk factors and the serum levels of 25-hydroxyvitamin D in the United States: data from the Third National Health and Nutrition Examination Survey. Arch Intern Med 2007;167:1159-65.

37. Huang Y, Li X, Wang M, Ning H, Lima A, Li Y, et al. Lipoprotein lipase links vitamin $\mathrm{D}$, insulin resistance, and type 2 diabetes: a cross-sectional epidemiological study. Cardiovasc Diabetol 2013;12:17.

38. Oh J, Weng S, Felton SK, Bhandare S, Riek A, Butler B, et al. 1,25(OH)2 vitamin D inhibits foam cell formation and suppresses macrophage cholesterol uptake in patients with type 2 diabetes mellitus. Circulation 2009;120:687-98. 